\title{
Performance Based Maintenance of Road Infrastructure by Contracting-A Challenge for Developing Countries
}

\author{
Masuda Sultana, Anisur Rahman, Sanaul Chowdhury \\ Griffith School of Engineering, Gold Coast Campus, Griffith University, Southport, Australia. \\ Email: \{m.sultana, a.rahman, s.h.chowdhury\}@griffith.edu.au
}

Received December $14^{\text {th }}, 2011$; revised February $23^{\text {rd }}, 2012$; accepted March $4^{\text {th }}, 2012$

\begin{abstract}
Road authorities always strive to reduce the maintenance costs of road infrastructure systems using various traditional methods of contract. Contracting out road maintenance to the private sector based on performance measures is an alternative solution to maintain road infrastructure in a cost-effective way and is named as Performance Based Maintenance Contracting (PBMC). Many countries have succeeded in minimizing road infrastructure maintenance costs using performance-based maintenance contracts over the last two decades. However, implementation of PBMC is still a challenge for many developing countries because of resource and skill limitations, corruption and poor management systems. This paper discusses and analyses the problems and difficulties in the successful implementation of PBMC in developing countries.
\end{abstract}

Keywords: Contract; Performance-Based Maintenance; Road Infrastructure; Developing Countries

\section{Introduction}

Road authorities always strive to reduce the maintenance costs of the road infrastructure system by using various traditional methods of contracting. Due to the emerging problems faced by road agencies in controlling the quality of maintenance works and the management of time and cost related to various traditional methods of contracting, some road agencies have started to consider privatization as an alternative solution to the problem. In the early 1990s, some experts and engineers started to introduce an efficient method called performance-based maintenance contracting (PBMC). If implemented successfully, it has the potential of reducing maintenance costs by $10 \%$ to $50 \%$. The use of PBMC also reduces agency risk and agency administrative burden [1].

PBMC has a successful record in minimizing infrastructure maintenance costs in many developed and developing countries over the last two decades. However, there are still obstacles in regard to introduce PBMC in developing countries. The main objective of this paper is to discuss and analyze the challenges in introducing and implementing PBMC effectively in developing countries.

\section{Performance-Based Maintenance Contracting (PBMC)}

Performance-based maintenance contracting (PBMC) for road infrastructure is a method under which the selected contractor has to plan, design and implement maintenance activities in order to achieve short and long term road condition standards for a fixed price, subject to specified risk allocation [2]. In PBMC, contractors have to take the high risk and obligation of the road maintenance work as they are responsible for the design and implementation of the project using their workforce.

When PBMC is developed carefully, it may motivate the contractors to implement better-quality maintenance practices to improve the overall condition of road assets during the contract period. Payments are made after checking that the contractor is meeting the performance standards properly as defined in the contract [1]. PBMC reduces the time and costs for road maintenance by applying well-organized and time saving work methods and technologies.

\section{Benefits of Performance Based Maintenance Contract}

This section briefly discusses the benefits of performance-based maintenance contract over the traditional methods of contract. The seven beneficial areas of PBMC identified are: cost savings, risk sharing, assurance of quality, availability of initial funding sources, achieving a sustainable road management system, increased flexibility, and increased transparency.

On average, the indirect costs to contractors are $21 \%$ lower in PBMC, since contractors can improve their in- 
ternal business process with more efficient manpower, equipment and materials due to the long term nature of PBMC [3]. Anastasopoulos, et al. [4] indicated that outsourcing very long road segments might not be as costsaving as shorter segments. On the other hand, projects with high in-house costs tend to perform better under PBMC or more likely to experience cost savings. However, application of PBMC is still at an early stage and road authorities and contractors will gain experience with time [5].

As by nature, PBMC requires less administrative effort, the road authority can maintain fewer in-house personnel than before [6]. This method can facilitate the highest level of skills and proficiency the road authority [7]. Hardy [8] argued that the reduced administrative staff are taken on mainly by the contractor. The role of the Consultant in earlier type of contract is absorbed by the contractor. Thus, the cost for one contract is saved and contractors achieve some expertise.

A change in method of specification from work output to performance allocates the risk exposure of the road authority to the service provider i.e. contractor $[9,10]$. The risk allocation to the contractor would be beneficial for the road authority only when a contractor would be able to manage the risk better.

International financing institutions have always provided assistance to developing countries and economies in the transition to develop a local construction industry. PBMC is also called output based aid (OBA) by the World Bank. Since the inauguration of first project using OBA in 2002-03, the World Bank has consequentially increased their funding from 32 projects to around 200 projects with various funding sources, which are anticipated to benefit at least 60 million poor people [11].

The road authority gets the option for the possibility of long-term sustainability in the management system using PBMC. Moreover, due to the longevity of the contract, staffs are able to understand the network and have enough time to implement initiatives based on this knowledge as well as understanding which areas of the network are under stress and how these areas are likely to react to extreme events [12].

The contractors receive flexibility in achieving their work target under PBMC. This flexibility can be enjoyed either by choosing the desired engineering design and drawing or by using innovative technology [13].

Traditional methods of contract are prone to corruption because of the nature of their decision making processes. PBMC has the potential to reduce the scale of the decision making process by promoting transparency and good governance in road maintenance works $[14,15]$. Thus PBMC can help limit the impact of corruption.

\section{Performance Based Maintenance Contracting in Developed Countries}

Various State Departments of Transportation (DOT) in USA started to outsource road maintenance works in order to reduce costs, increase efficiency, improve quality, expedite project delivery, spur innovation, enhance risk management, and overcome a lack of expertise [16]. Performance-based maintenance contracts were first introduced in the state of Virginia in 1996. Since then, other states, such as Alaska, Florida, Oklahoma, Texas, and North Carolina have started applying PBMC approaches to maintain highways, bridges, tunnels, rest areas, and urban streets. In September 2001, the Oklahoma Department of Transportation (DOT) entered into two five-year contracts valued at approximately US\$36 million. The contracts covered routine maintenance, such as pothole and guardrail repair, snow and ice removal, sign repair and litter pickup, but not major items such as pavement preservation or bridge repair. As the contractors failed to meet the required performance, the contracts were cancelled in May, 2002. Texas DOT also expected savings in their pilot PBMC. However, one of their special areas of concern was the contractor's performance in pavement maintenance [17].

In 1995, the construction industry of Australia was introduced to PBMC (called performance specified Maintenance Contract, PSMC in Australia and New Zealand) for the maintenance of a large proportion of the arterial road network in Sydney, New South Wales. PBMC is expected to provide a quality road network to road users at a reduced cost, free of the many risks which traditionally, enhance effective road management [9]. Examples of the results which have been reported are as follows [18]:

- Sydney, New South Wales-38\% savings.

- Southern Tasmania-20\% savings.

- North Island, New Zealand-15\% savings.

- South Perth, Western Australia-25\% savings.

- Mid North Region, Western Australia-30\% savings [18].

Therefore, the performance-based model is consistently delivering savings in excess of 35 percent compared to in-house operations [18]. According to Keir and Blerk [12], longevity, security and strategically long term view were the beneficial factors of PBMC enjoyed by four trialed sites maintained by PBMC in New Zealand. Some disadvantages of the PBMC model mentioned by Keir and Blerk [12] were as follows:

- The critical part of long-term contracts is working to achieve shared goals and respecting each party's individual goals. If any party fails to maintain the harmony, the contract can be a disaster.

- If the right people are not available and a transition period cannot be undertaken the contract is placed un- 
der considerable risk. A new person coming into a PBMC in a senior role without understanding the nature of the relationships or the various goals and strategies, can do significant damage. Also the loss of network and systems knowledge can be significant.

- Pavement modeling on long term contracts is critical in terms of understanding the financial cost of maintaining KPI's (Key Performance Indicators) at a particular level and it is a very high risk area if the modeling predictions are not right.

\section{Performance Based Maintenance Contracting (PBMC) in Developing Countries}

The applications of PBMC have been observed in many developing countries, such as Argentina (1990), Uruguay (1996), Chile (1997), Brazil (1998), Chad, Peru, and Guatemala, Finland, Estonia, Serbia and Montenegro, South Africa, Zambia, Chad, the Philippines.

Although PBMC has been successful in the developed countries, it has been observed that the implementation of PBMC becomes challenging for developing countries. There are a few literature discussing the disadvantages and impediments of PBMC. Pakkala [19], Zietlow [1], Zietlow [1,5], Zietsman [20], Queiroz [21], Hardy [8], Austroads Inc. [22] and Hyman, et al. [23] have briefly mentioned some drawbacks and impediments of PBMC. As stated by Hardy [8], high cost of tendering, decreased competition among the contractors, increased significance of poor contractor's performance, reduced ability to deal with changes, reduction of technical capability within the road agency, loss of control of the network, loss of innovation to the public domain are some drawbacks of PBMC.

The literature review and survey of the current research helped to figure out some factors that are becoming the main challenges for developing countries during the introduction of PBMC. The factors are discussed in the next section.

\section{Challenges for the Developing Countries}

The challenges that work as a barrier during the introduction of PBMC in developing countries are as follows: lack of support from government, dependency on external funding, political influence and corruption, lack of experience in introducing PBMC, lack of proper planning, fear of losing job, loss of competition, loss of control of the network, contractors' performance and attitude, challenges in estimating the cost of PBMC.

\subsection{Support from Government}

Most developing countries have internal issues related to building a sustainable infrastructure system. It is evident that the government of a developing country has always given priority to construct new roads than maintaining existing ones. The construction project of building new roads seems to be more attractive than the maintenance of older one to draw the attention of general public. The scenario of Bangladesh which is a developing country of south Asia can help understanding the problem. The current research shows that bureaucracy among the various ministries and fund shortage for road maintenance projects cause delays in allocating fund for road maintenance works in Bangladesh. When the roads become almost unusable or majority of people criticize the government's effort towards road maintenance, government immediately manages to allocate some fund to stop the peoples' outrage. However, the implementation of PBMC requires continuous government support towards this privatization approach due to the long-term nature of the performance-based maintenance contracts.

This study finds that governments in developing countries, who are already facing funding shortages in other sectors, hesitate to provide funding for long-term PBMC at its early stage. Moreover, government shows interest for investing in long-term PBMC approach only if the initial cost of introducing PBMC is supported by any external funding authority.

\subsection{Dependency on External Funding}

The government of Chad started the process of contracting out roads to the private sector in 1994. When the International Development Association provided funding as part of its efforts to support an efficient and sustainable transport infrastructure, the Chad Government started contracting out road maintenance work using performance measures in 2001. The contractor successfully improved the road condition to an expected satisfactory level [24].

The analysis of this research shows that getting support from an external authority can only be a temporary solution for developing countries as providing fund is mainly dependent on the donor's willingness to support the country. If the donors are not satisfied with the road authority or the government for any reason, they may suspend or cancel the loan. It may severely affect the construction project and the country has to confront difficulties in implementing the project. The suspension of external loans of US \$2.9 billion for the Padma Multipurpose Bridge Project construction in Bangladesh is an example of the negative side of dependency on donor funding. The lead financier World Bank suspended the loan on September, 2011 while the construction work of the bridge was planned to start in 2012 [25]. As a result of the World Bank's decision towards the project, other 
financiers also suspended the loan.

This study suggests that before introducing PBMC in a developing country, the road authorities should ensure the source of internal funding as early as possible.

\subsection{Political Influence and Corruption}

Political influence and corruption are the hardest obstacles for any new concepts to be implemented in developing countries. The selection of contractor for road maintenance works in developing countries is sometimes influenced by the political leaders. The reports of local newspaper mentioned that the World Bank suspended the Padma Bridge Project loan alleging the involvement of a company in corruption in order to illegally win the bid of supervising the construction works of the main bridge costing around US\$50 million [25]. However, the reduction of influence and corruption in the construction and maintenance works is the willingness of the government, ruling political party, and influential elite people of a country. Any new approach may be able to reduce it for a while, but it requires massive cultural and economic changes as a whole in developing countries.

The literature showed that the construction of new roads is the means of becoming popular and securing future votes among the local elite and politicians in Bangladesh. Corruption is very widespread in Roads and Highways Department (RHD) of Bangladesh from engineering material supply to the selection of the contractor [26]. According to the local newspapers' reports, vehicular traffic on 290 Kilometre Dhaka-Chittagong highway has become so intense and chaotic that a journey between the capital city and port city could take as long as 15 hours. Lack of maintenance and repairs for years have created potholes and even large ditches at various places of the busy highway, causing further delay and severe damages to the vehicle.

The Asian development Bank (ADB) helps to introduce PBMC in Bangladesh. Routine and recurrent road maintenance work for about $50 \mathrm{~km}$ of regional or district roads would be contracted out to domestic contractors based on performance-based contracts for 3 years [27]. However, two performance-based routine road maintenance contracts were run by ADB form January, 2008 to January, 2011 in Bangladesh. The analysis done on anonymous survey suggests that there is still possibility of political influence and corruption in various forms in these contracts.

There is really very few evidence of PBMC reducing the chance of corruption. In PBMC, road authority officials will supervise the site to check the performance of the contractors. If these officials would take bribes during these checks, the situation will be worse than ever. This study suggests that the contract documents are needed to be strictly prepared and implemented in PBMC. Otherwise, there is no guarantee that PBMC will be free of political influence and corruption in developing countries.

\subsection{Lack of Experience on and Knowledge of PBMC}

In Indonesia, during the introduction of PBMC, government agencies were considered to be capable of undertaking a pilot trial of PBMC. However, providing training to the staff on the new approach was necessary so that they could adapt to their new roles and responsibilities [28].

The findings of this research show that inadequate experience on and knowledge of performance-based contracts are a great challenge for developing countries. The experienced personnel are required to decide the proper maintenance project, prepare all the relevant contract documents, set up the appropriate performance standard for the country, train the staff and contractors, and prepare the guidelines for the trial project of PBMC. The study also suggests that in the case of highly deteriorated road condition, the roads should be rehabilitated first before starting PBMC. Experience is really important in deciding all the factors discussed above. Developing countries are also consulting overseas contractors experienced in PBMC.

\subsection{Lack of Proper Planning}

Another challenge for developing countries in the introduction of PBMC is the lack of proper planning and managerial skills. The literature review and this research suggest that lack of planning can cause loss of quality in the first trial of PBMC.

PBMC requires a cultural and procedural change in the road authority. The road authority should plan a systematic way for moving to PBMC. They need good data storage on previous road maintenance projects, a longterm source of funding, a good contract document, training and future planning for the staffs losing the job and determination of projects that is suitable for the pilot trial of PBMC. The road authority should set up a way of tracking any kind of possible savings that can be incurred by PBMC.

\subsection{Fear of Losing Job}

Another beneficial side of PBMC mentioned in the literatures is to reduce the number of staff in road authorities. The survey of this research shows that sometimes fear of losing jobs may refrain government staff in developing countries to support PBMC. The research also shows that government sector jobs are more secured than 
private sector jobs in some developing countries. The staff and union may not cooperate in implementing PBMC due to these reasons.

A road authority should consider the consequences of the reduction of the staff before introducing PBMC. The government's road authority should have the sufficient technological capability to improve the road infrastructure system with increasing population and upcoming technologies in the future. The cut down of staff should not be so extreme that the road authority in a developing country has to depend on private sector for research and development in future.

\subsection{Loss of Competition}

PBMC transfers the risk and the responsibility of design and the management of the project to the contractors. The size of the contractors must be large enough to take such responsibilities. On the other hand, preparation of tender documents involves a set of typical contract documents, compilation and verification of asset inventtory and condition data. It also requires the calculation of programs and estimation to be used in the tender evaluation [8]. As the cost of bidding was high, the resulting number of tenderers after prequalification phase for performance-based contracts in Tasmania and Western Australia was only four in the early stage of introducing PBMC [29].

The literature review and analysis shows that the number of contractors bidding in PBMC type tendering is very few due to the high cost of tendering and bidding. This can reduce the competition among the contractors and increase the fear in small contractors of losing their work. However, small contractors can work together as a union to get jobs.

\subsection{Loss of Control of the Network}

The CREMA experience in Brazil indicated that under performance based contracts, contractors needed to have sufficient flexibility to determine an optimized mix of technical solutions and an optimized execution schedule, without any interference from the employer [13]. The road authorities have a common anxiety of losing the control over the network as PBMC gives flexibility to the contractors to choose their own work methodologies. Failure in setting performance standards in the early stages of PBMC can create a disastrous situation. The termination of the contract costs a significant amount of money and disputes in PBMC compared to the traditional contracts which can be hard to handle for the road authority in a developing country.

\subsection{Performance and Attitude of Contractors}

As PBMC is dependent on the performance of the con- tractors, the contractors must be capable enough to adapt the approach. The literature suggested that poor performance of the contractors has been observed in some contracts. The necessary training and information on the new contract should be provided prior to the implementation of PBMC. The road authority should track the level of service provided by the contractors in PBMC. Contractors are also required to be motivated to enjoy the benefits of the new method.

\subsection{Challenges in Estimating the Cost}

The literature review and research suggest that the successful implementation of PBMC requires the proper estimation of costs. Contract terms, documents and performance standard will vary in different countries. As PBMC is a long-term contract, it will not be possible to change anything once the contract has been started. However, this research finds that developing countries faced difficulties in estimating costs at an early stage of implementing PBMC as it is a very new concept for them.

\section{Conclusion}

A strong road infrastructure system is the backbone of poverty eradication and maintaining a sustainable socioeconomic structure in developing countries. PBMC is a new concept designed to resolve the problems related to traditional methods of contracting and has significant potential to improve the maintenance and management of road infrastructure. Some developing countries have already implemented PBMC while some other countries are currently considering PBMC for their road infrastructure system. This paper reviewed and analyzed a large amount of published information and literature to examine the effectiveness of PBMC in developing countries. This paper also discussed and analyzed the challenges and barriers that affect the implementation of PBMC in developing countries. This concept is still in its early stage and has huge potential and scope of work for future researchers. The potential of reducing maintenance costs, increasing the quality of works and reducing the chance of corruption in the long run in developing countries are the challenging issues for PBMC, which needs more attention. Further research can be carried out on the challenges discuss in this paper to implement PBMC successfully in the developing countries.

\section{REFERENCES}

[1] G. J. Zietlow, “Cutting Costs and Improving Quality through Performance-Based Road Management and Maintenance Contracts-The Latin American and OECD Experiences," Senior Road Executives Programme, Restructuring Road Management, German Development Cooperation, Birmingham, 2005. 
[2] M. Frost and C. M. Lithgow, "Future Trends in Performance-Based Contracting-Legal and Technical Perspectives,” Proceedings of 19th ARRB Conference, Sydney, 7-11 December 1998, pp. 91-101.

[3] A. Straub, “Cost Savings from Performance-Based Maintenance Contracting," International Journal of Strategic Property Management, Vol. 13, No. 3, 2009, pp. 205-217. doi:10.3846/1648-715X.2009.13.205-217

[4] P. C. Anastasopoulos, B. G. McCullouch, K. Gkritza, F. L. Mannering, and K. C. Sinha, "A Cost Savings Analysis of Performance-Based Contracts for Highway Maintenance Operations” Journal of Infrastructure Systems, Vol. 16, No. 4, 2010, pp. 251-263.

doi:10.1061/(ASCE)IS.1943-555X.0000012

[5] G. J. Zietlow, "Performance-Based Road Management and Maintenance Contracts-Worldwide Experiences,” International Seminar on Road Financing and Investment, Arusha, 16-20 April 2007, pp. 1-76.

[6] N. Stankevich, N. Qureshi and C. Queiroz, "PerformanceBased Contracting for Preservation and Improvement of Road Assets,” The World Bank, Washington DC, 2005.

[7] G. J. Zietlow and A. Bull, "Performance Specified Road Maintenance Contracts-The Road to the Future, the Latin American Perspective,” 21st World Congress, Kuala Lumpur, 3-9 October 1999, pp. 1-6.

[8] P. Hardy, "Austroads Review of Performance Contracts: The Potential Benefits of Performance Contracts," Opus International Consultants, Nelson, 2001.

[9] M. Frost and C. Lithgow, "Improving Quality and Cutting Costs through Performance Contracts-Australian Experience,” World Bank Road Management Training Seminar, Washington DC, 1996.

[10] B. Carpenter, E. Fekpe and D. Gopalakrishna, "Performance-Based Contracting for the Highway Construction Industry, an Evaluation of the Use of Innovative Contracting and Performance Specification in Highway Construction,” Koch Industries Inc., Washington DC, 2003.

[11] Y. Mumseen, L. Johannes and G. Kumar, "Roads, Chapter 4, Output-Based Aid: Lessons Learned and Best Practices,” The World Bank, Washington DC, 2010.

[12] M. Keir and G. V. Blerk, "A Review of the Performance Specified Maintenance Contract (PSMC) Model Using a Case Study of PSMC 001, Case Study-Transit New Zealand,” Transfield Services, Sydney, 2006.

[13] E. Lancelot, "Performance Based Contracts in the Road Sector: Towards Improved Efficiency in the Management of Maintenance and Rehabilitation Brazil's Experience,” The World Bank Group, Washinton DC, 2010.

[14] G. Liautaud, "Maintaining Roads: Experience with Output-Based Contracts in Argentina Chapter 4, Contracting for Public Services, Output-Based Aid and Its Applications,” The World Bank, Washington DC, 2001.

[15] G. J. Zietlow, "Implementing Performance-Based Road Management and Maintenance Contracts in Developing Countries, an Instrument of German Development Cooperation, Birmingham,” German Development Cooperation, Frankfurt, 2004.
[16] G. F. Segal, A. T. Moore and S. McCarthy, "Contracting for Road and Highway Maintenance,” Reason Foundation, Reason Public Policy Institute, Los Angeles, 2003.

[17] N. Ribreau, “Synopsis of WSDOT's Review of Highway Maintenance 'Outsourcing' Experience, Transportation Research Board Committee A3C01 Maintenance and Operations Management," Washington State Department of Transportation Maintenance and Operations, Washington DC, 2004.

[18] M. Frost, "Imperatives in Future Road System Management, Improved Road Maintenance Productivity-The Australian Case," 14th IRF Road World Congress, Paris, 11-15 June 2001, pp. 1-20.

[19] P. Pakkala, "Innovative Project Delivery Methods for Infrastructure an International Perspective,” Finnish Road Enterprise, Helsinki, 2002.

[20] J. Zietsman, "Performance Measures for Performance Based Maintenance Contracts,” Texas Transportation Institute, Houston, 2004.

[21] C. Queiroz, "Options for Implementing PerformanceBased Contracts,” Transport Forum, Washington DC, 2005.

[22] Austroads Inc., "Development of Performance Contracts and Specifications-Full Report, Opus International Consultants, New Zealand,” Austroads Inc., Sydney, 2003.

[23] W. A. Hyman, AASHTO and Federal Highway Administration, "Performance-Based Contracting for Maintenance, A Synthesis of Highway Practice, NCHRP Synthesis 389,” Transportation Research Board, Washington DC, 2009.

[24] T. Hartwig, Y. Mumssen and A. Schliessler, "Output Based aid in Chad Using Performance-Based Contracts to Improve Road,” OBApproaches, Washington DC, 2005.

[25] The Daily Star, "Published Article on Padma Multipurpose Bridge Project on September 30, October 10, 15-17, 26, November 30, 2011,” The Daily Star, Dhaka, 2011.

[26] Transparency International Bangladesh, "Corruption in Public Sector Departments: Its Manifestations, Causes, and Suggested Remedies, a Report on the Findings of Four Diagnostic Studies on Corruption Conducted for the World Bank, Transparency International Bangladesh,” 2002.

http://unpan1.un.org/intradoc/groups/public/documents/a pcity/unpan004882.pdf

[27] Asian Development Bank, "Report and Recommendation of the President to the Board of Directors on a Proposed Loan to the People's Republic of Bangladesh for the Road Network Improvement and Maintenance Project,” Asian Development Bank, Mandaluyong, 2002.

[28] Opus International Consultants Ltd., "Introducing Performance Based Maintenance Contracts to Indonesia Framework Document,” MWH Limited, Wellington, 2006.

[29] P. Robinson, "Road Maintenance by Contract-What are the Risks and Benefits?” International Congress on Local Government Engineering and Public Works: Incorporating 10th National Local Government Engineering Conference, Sydney, 22-26 August 1999, pp. 67-75. 